\title{
The potential role of HGF-MET signaling and autophagy in the war of Alectinib versus Crizotinib against ALK-positive NSCLC
}

Xing Huang ${ }^{1,2,3}$ (D)

\begin{abstract}
Non-small-cell lung cancer (NSCLC) is currently the leading cause of cancer-related death. Accumulating evidences suggest that overcoming the therapeutic resistance in NSCLC is a big challenge. Recently, the outcomes of two independent phase 3 trials regarding Alectinib versus Crizotinib in ALK-positive NSCLC are encouraging. However, given the potential relevance of HGF-MET signaling and especially autophagy to the war against ALK-positive NSCLC between Alectinib and Crizotinib, it's too early to reach a convincing conclusion. Therefore, to further improve the therapeutic efficacy of ALK-positive NSCLC, this commentary highlights the negligence in design of relevant clinical trials, emphasizes the importance of molecular characteristics investigation, and discusses the prospect of combination therapy.
\end{abstract}

Keywords: NSCLC, ALK-targeted therapy, Alectinib, Crizotinib, HGF-MET signaling, Therapeutic resistance, Autophagy, LIR motif, Combined treatment

\section{Background}

Non-small-cell lung cancer (NSCLC) is currently one of the leading cause of cancer-related death. Accumulating evidences suggest that overcoming the therapeutic resistance in NSCLC is a big challenge. Recently, two independent phase 3 trials regarding Alectinib versus Crizotinib in ALK-positive NSCLC, have been individually reported by Solange Peters et al. [1] in NEJM and Toyoaki Hida et al. [2] in Lancet. The outcomes are encouraging, and I appreciate the concerted effort for improving therapeutic efficacy in NSCLC. However, after careful analysis and consideration, I think it's too early to reach a conclusion, because the both trials utterly neglect several key points and challenges that are highlighted as follows.

Correspondence: dr.huangxing@foxmail.com

${ }^{1}$ Key Laboratory of Precision Diagnosis and Treatment for Hepatobiliary and Pancreatic Tumor of Zhejiang Province, First Affiliated Hospital, School of Medicine, Zhejiang University, 79 Qingchun Road, Zhejiang, Hangzhou 310003, China

${ }^{2}$ The Key Laboratory of Developmental Genes and Human Disease, Institute of Life Sciences, Southeast University, Nanjing, Jiangsu 210096, China Full list of author information is available at the end of the article

\section{Main text}

First, Crizotinib is actually an ALK/MET doubletargeted small molecule inhibitor. Hepatocyte growth factor (HGF) and its physiological receptor tyrosine kinase MET (HGFR) have been reported involved in almost all the aspects of cancer progression, including cancer development, growth, invasion and metastasis. HGF-MET signaling activates AKT- and ERKmediated cancer cell survival, cycle, proliferation, motility and transformation. The significance of HGF-MET signaling makes them become critical targets in cancer therapy [3]. Unexpectedly, besides cancer cells themselves, MET also regulates cancer immune microenvironment. For instance, MET is required for recruitment and infiltration of anti-tumor neutrophil to abate metastasis [4]. The paradoxical effects of MET ought to force us to re-investigate whether it is really an applicable target in cancer therapy. Therefore, the states of MET and its ligand HGF need to be taken into consideration in the design and analysis of clinical trials. Alectinib 
combined with MET-targeted inhibitor versus Crizotinib is a more reasonable comparison.

Second, Crizotinib is able to induce autophagy in NSCLC [5]. Autophagy is a protective mechanism that is usually linked to cancer metabolic stress and therapeutic resistance, mainly on "self-eating" to recycle obsolete components to maintain necessary biogenesis for cancer survival. In fact, combined treatment with ALK inhibitor and autophagy blocker, like Chloroquine (CQ) or 3-Methyladenine (3-MA), can dramatically suppress cancer cell viability and colony formation in many kinds of NSCLC [6]. This indicates autophagy plays a pivotal role in ALK-driven onco-signalings, and autophagic state is likely to determine ALK-targeted therapeutic efficacy in NSCLC.

Furthermore, ALK contains the typical LC3interacting region (LIR) motif. LIR motif is the principal structural foundation for autophagy machinery [7]. By virtue of bioinformatics analysis, seventeen various types of LIR motifs are identified in MAM1, MAM2, TM, PTK domains or other regions of ALK (Table 1), which means there may be a direct interplay between ALK and autophagy. Of note, some of LIR motifs locate in kinase activity center of ALK. Given that de-phosphorylation in LIR motif has been proved capable to enhance its interaction with LC3 [8], a crucial issue arises: should we just focus on inhibiting the kinase activation in ALK-targeted therapy for NSCLC? Because if only targeting kinase activity, ALK may immediately turn to induce autophagy for resisting cancer therapeutic stress via its inactivation-caused de-phosphorylated LIR motif. It

Table 1 Potential LIR Motif in ALK

\begin{tabular}{lllll}
\hline No & Position & Domain & Type & Sequence \\
\hline 1 & $46-49$ & Extracellular & Y & YSRL \\
2 & $253-256$ & Extracellular & F & FPFL \\
3 & $290-293$ & MAM1 & W & WRRI \\
4 & $320-323$ & MAM1 & F & FLLL \\
5 & $386-389$ & MAM1 & W & WTVL \\
6 & $419-422$ & MAM1 & F & FFAL \\
7 & $587-590$ & MAM2 & Y & YEGL \\
8 & $595-598$ & MAM2 & W & WMVL \\
9 & $625-628$ & MAM2 & F & FDNI \\
10 & $635-638$ & MAM2 & Y & YLTI \\
11 & $772-775$ & Extracellular & Y & YILV \\
12 & $1052-1055$ & TM & F & FSGl \\
13 & $1127-1130$ & PTK & F & FGEV \\
14 & $1193-1196$ & PTK & F & FILL \\
15 & $1315-1318$ & PTK & F & FGVL \\
16 & $1376-1379$ & PTK & F & FAll \\
17 & $1401-1404$ & Intracellular & Y & YGPL \\
\hline
\end{tabular}

seems like "when one door shuts, another opens", and will be a big challenge for all the ALK-targeted therapies (including but not limited to NSCLC).

In addition, as one coin has two sides, emerging evidences suggest that autophagy has mutually contradictory effects on cancer [9]. For example, cancer cell autonomous autophagy is required for chemotherapyinduced immune surveillance by releasing ATP to activate immunocytes, whereas surrounding normal cellsgenerated micro-environmental autophagy promotes tumor growth by supplementing abundant extrametabolites. Moreover, autophagy has distinct phasedependent functions in cancer progression, for example, preventing malignant transformation, but favoring growth and metastasis [10]. Thus, it's in dire need to divide ALK-positive NSCLC into molecular characteristics of HGF-MET signaling or / and autophagy-based sub-types for recruitment of the most eligible patients.

\section{Conclusions}

Taken together, even the both trials provide strong evidences supporting the superiority and safety of Alectinib in comparison with Crizotinib in ALK-positive NSCLC, I still strongly suggest authors further investigate potential roles of HGF-MET signaling and autophagy in determining sensitivity or resistance to ALK-targeted therapy for NSCLC. On the other side, since the anti-cancer effects and safety of autophagy blocker have been testified in several cancer therapies, ALK-autophagy doubletargeted strategy maybe a simple and practicable method to improve NSCLC therapeutic efficiency in the future.

\section{Abbreviations}

3-MA: 3-Methyladenine; CQ: Chloroquine; HGF: Hepatocyte growth factor; LIR: LC3-interacting region; NSCLC: Non-small-cell lung cancer

\section{Acknowledgements \\ The author would like to deeply thank editors and reviewers for their efforts in improving the quality and impact of this commentary.}

\section{Funding}

This work was supported by grants from National Natural Science Foundation of China (81502975), and China Postdoctoral Science Foundation (2016 T90413 and 2015 M581693). The research was funded in part by Jiangsu Planned Projects for Postdoctoral Research Funds (1501002A) and the Fundamental Research Funds for the Central Universities (2242016R20027 and 2242016 K41045).

\section{Availability of data and materials}

All data generated or analyzed during this study are included in the current article. Further information is available from the corresponding author on reasonable request.

\footnotetext{
Authors' contributions

$\mathrm{XH}$ conceived the commentary, performed the bioinformatics analysis and found the LIR motif in ALK, and wrote the manuscript. The author read and approved the final manuscript.
}

Ethics approval and consent to participate Not applicable. 


\section{Consent for publication}

Not applicable.

\section{Competing interests}

The author declares that he has no competing interests.

\section{Publisher's Note}

Springer Nature remains neutral with regard to jurisdictional claims in published maps and institutional affiliations.

\section{Author details}

'Key Laboratory of Precision Diagnosis and Treatment for Hepatobiliary and Pancreatic Tumor of Zhejiang Province, First Affiliated Hospital, School of Medicine, Zhejiang University, 79 Qingchun Road, Zhejiang, Hangzhou 310003, China. ${ }^{2}$ The Key Laboratory of Developmental Genes and Human Disease, Institute of Life Sciences, Southeast University, Nanjing, Jiangsu 210096, China. ${ }^{3}$ The Therapeutic Antibody Research Center of SEU-Alphamab, Southeast University, Nanjing, Jiangsu 210096, China.

Received: 9 January 2018 Accepted: 13 February 2018

Published online: 20 February 2018

\section{References}

1. Peters S, Camidge DR, Shaw AT, Gadgeel S, Ahn JS, Kim DW, Ou SI, Perol M, Dziadziuszko R, Rosell R, et al. Alectinib versus Crizotinib in untreated ALKpositive non-small-cell lung cancer. N Engl J Med. 2017;377(9):829-38.

2. Hida T, Nokihara H, Kondo M, Kim YH, Azuma K, Seto T, Takiguchi Y, Nishio M, Yoshioka H, Imamura F, et al. Alectinib versus crizotinib in patients with ALK-positive non-small-cell lung cancer (J-ALEX): an open-label, randomised phase 3 trial. Lancet. 2017;390(10089):29-39.

3. Furlan A, Kherrouche Z, Montagne R, Copin MC, Tulasne D. Thirty years of research on met receptor to move a biomarker from bench to bedside. Cancer Res. 2014;74(23):6737-44.

4. Finisguerra V, Di Conza G, Di Matteo M, Serneels J, Costa S, Thompson AA, Wauters E, Walmsley S, Prenen H, Granot Z, et al. MET is required for the recruitment of anti-tumoural neutrophils. Nature. 2015;522(7556):349-53.

5. You L, Shou J, Deng D, Jiang L, Jing Z, Yao J, Li H, Xie J, Wang Z, Pan Q, et al. Crizotinib induces autophagy through inhibition of the STAT3 pathway in multiple lung cancer cell lines. Oncotarget. 2015;6(37):40268-82.

6. Mitou G, Frentzel J, Desquesnes A, Le Gonidec S, AlSaati T, Beau I, Lamant L, Meggetto F, Espinos E, Codogno P, et al. Targeting autophagy enhances the anti-tumoral action of crizotinib in ALK-positive anaplastic large cell lymphoma. Oncotarget. 2015;6(30):30149-64.

7. Rogov V, Dotsch V, Johansen T, Kirkin V. Interactions between autophagy receptors and ubiquitin-like proteins form the molecular basis for selective autophagy. Mol Cell. 2014;53(2):167-78.

8. Liu L, Feng D, Chen G, Chen M, Zheng Q, Song P, Ma Q, Zhu C, Wang R, Qi $W$, et al. Mitochondrial outer-membrane protein FUNDC1 mediates hypoxiainduced mitophagy in mammalian cells. Nat Cell Biol. 2012;14(2):177-85.

9. Levy JMM, Towers CG, Thorburn A. Targeting autophagy in cancer. Nat Rev Cancer. 2017;17(9):528-42.

10. Janku F, McConkey DJ, Hong DS, Kurzrock R. Autophagy as a target for anticancer therapy. Nat Rev Clin Oncol. 2011;8(9):528-39.

\section{Submit your next manuscript to BioMed Central and we will help you at every step:}

- We accept pre-submission inquiries

- Our selector tool helps you to find the most relevant journal

- We provide round the clock customer support

- Convenient online submission

- Thorough peer review

- Inclusion in PubMed and all major indexing services

- Maximum visibility for your research

Submit your manuscript at www.biomedcentral.com/submit
Biomed Central 